\title{
Idiom understanding in people with Asperger syndrome/high functioning autism
}

\author{
Compreensão de expressões idiomáticas em pessoas com \\ síndrome de Asperger/autismo de alto funcionamento
}

\author{
Ioannis Vogindroukas ${ }^{1}$, Olga Zikopoulou ${ }^{2}$
}

\begin{abstract}
Purpose: To extend previous research in the development of idiom comprehension by investigating this ability in children with Asperger Syndrome (AS) or with High Functioning Autism (HFA). Methods: Three groups participated in the study. The first group consisted of 27 children with AS/HFA (mean age 11.3 years) and the other two consisted of typically developing children and adults, respectively. The Comprehension Test of Idiomatic Phrases (CTIP) was administered to all participants. Results: Children with AS/ HFA had lower performance compared to the other two groups. No difference was found in the performance between the two typically developing groups. Also, there was no significant correlation between the IQ and the performance for the children with AS/ HFA, while positive correlations were revealed between performance and age for the two groups of children. Conclusion: The results provide further evidence that children with AS/HFA have difficulties in understanding idioms and they confirm their tendency to make literal interpretations. These impairments are irrelevant to their intelligence and they affect their communication with others. The understanding of these difficulties is important in order to find ways to limit the confusion and the misinterpretations which are observed during the communicative acts with this clinic group.
\end{abstract}

Keywords: Comprehension; Aptitude; Psycholinguistics; Child language; Cognition; Asperger syndrome; Autistic disorders

\section{INTRODUCTION}

The acquisition of non literal - figurative language is a key issue in language development, because it depends on the interrelationships between linguistic, cognitive, and pragmatic skills. Linguistic skills on its own are not able to explain the ability to process and acquire figurative language. This is true if we consider that the traditional components of language, phonetics, semantics, and syntax, adequately characterise the structure of language, but they can not explain the variety and richness of meanings that arise whenever language is used to communicate. Idioms are key components of non literal language. An idiom is a phrase where combined words have a meaning that is different from the dictionary definitions of the individual words and from the literal definition of the phrase itself. An idiom functions as a single unit and it is syntactically

Este estudo foi realizado no Medical Psycho-Pedagogical Centre of North Greece - Thessaloniki, Grécia.

(1) Medical Psycho-Pedagogical Centre of North Greece - Thessaloniki, Grécia.

(2) Departamento de Política Educacional e Social, University of Macedonia - Thessaloniki, Grécia.

Endereço para correspondência: Ioannis Vogindroukas. Medical PsychoPedagogical Centre of North Greece. Giannitson 52, 54627, Thessaloniki, Greece. E-mail: vogindroukas@yahoo.com

Recebido em: 25/10/2010; Aceito em: 29/3/2011 fixed and semantically conventionalized. The meaning of idioms is often thought to be metaphorical or proverbial ${ }^{(1)}$.

It is strongly suggested that in typical development acquisition of idiom meaning is an ongoing process, extending from late childhood to adolescence ${ }^{(2)}$. Interestingly, studies have proved that ability to acquire the figurative meaning of idioms goes beyond 18 years into adulthood ${ }^{(3,4)}$. Researchers mostly agreed that individuals gradually increase their accuracy of idiom explanations during late childhood and adolescence, and then continuously improve it in adulthood. More specifically, the acquisition of the skills and abilities which are used to understand figurative language is placed between 7 and 11 years of age ${ }^{(5)}$. Before 7 years of age, young children have the tendency to interpret idioms literally. Progressively the pieceby-piece literal interpretation is suppressed and more mature forms of elaboration, namely figurative, become apparent. The most dramatic change in the figurative language process is placed at the age of 8 years, when the literal interpretation gives place to the elaboration of contextual information ${ }^{(5)}$. More recent studies show that the language processing skills that aid idiom comprehension are still not fully developed until 11-12 year-olds ${ }^{(6)}$ and so incomplete understanding of these expressions is still present in adolescents ${ }^{(7)}$. In adults, moderate age-related improvements are observed between 19 and 55 years of age ${ }^{(2)}$. It is already known that children with language 
comprehension problems and language-based learning disabilities present significant difficulties in figurative language interpretation. These difficulties are due to their tendency to understand language literally, their deficiencies in pragmatic skills and/or their difficulties in reading comprehension ${ }^{(8)}$.

Pragmatics is the domain of language concerned with how speakers use language to have a successful communication. It can be defined as the conventions and rules which govern communication. These conventions and rules may concern the social knowledge (such as an appropriate use of language for communication with friends as opposed to adults) or sociocognitive understanding (such as trying to understand the relationship between what speakers say and what they mean or intend to communicate). Thus, the ability to communicate is based on higher order abilities, while knowledge of context and language and interacting cognitive systems can combine to generate novel inferences that are specific to each communicative act. For this reason pragmatic language is considered the most complex aspect of linguistic functioning and necessary for understanding both what speakers say and what is implicit in their utterance ${ }^{(9)}$. This is not surprising, if we take into consideration that much of what we need to understand in order to communicate with language is not directly stated, written, or depicted, but we succeed in understanding it because we construct meaning via a process of inference ${ }^{(10)}$.

Inferencing is a key component of pragmatics, as meaning is constructed by making connections between information and linking information together ${ }^{(11)}$. The same expression can have a different meaning in different communicative situations and, by exploiting context it is possible to understand the speaker's intention. This means that understanding and using language involves not only decoding the text but also the construction of meaning through the integration of knowledge and text, via a process of inference ${ }^{(11)}$. Inference can be seen as a cognitive process connecting information from different sources. It is an especially important ability when deriving an implied meaning of an utterance, as shown by studies about text comprehension in children ${ }^{(6)}$.

Asperger syndrome (AS) and high-functioning autism (HFA) are characterized by impairments in the development of communication and social skills. Specifically, the diagnosis of Asperger syndrome (AS) refers to individuals who have no history of language delay, their cognitive development is within the normal range, but they have significant social and communicative disability and restricted, repetitive, and stereotyped patterns of behavior, interests, and activities. On the other hand, the diagnosis of HFA is referred to individuals with autism who function in the normal range of IQ ${ }^{(12)}$. Children with AS/HFA exhibit unsuccessful pragmatic communication, even when their language is fluent or even pedantic ${ }^{(13)}$. These pragmatic impairments affect the children's ability to infer the implication of an utterance and to make inferences from social scripts, metaphors and speech acts ${ }^{(10)}$. The pragmatic impairments in children with AS are strongly supported by many researchers. More specifically, these pragmatic impairments include impairments of comprehension, including misinterpretations of literal/implied meanings and understanding of figurative language ${ }^{(14)}$. These characteristics are included in the diag- nostic criteria proposed by the DSM-IV (1994) as difficulties in modes of non verbal communication and in conversation. The above difficulties are independent from the vocabulary, grammar or verbal IQ ${ }^{(15)}$. In fact, some children with AS have the tendency to talk like an adult with an advanced vocabulary and to use quite complex sentences. This means that the formal structure of language is usually intact, but the ability to use language to engage socially is compromised, suggesting pragmatic impairments ${ }^{(16)}$ and poor knowledge about the social rules of appropriate communication ${ }^{(9)}$.

Many studies provide evidence for a deficit in inference in AS and in HFA, reporting that subjects have particular difficulty in different kinds of tasks demanding pragmatic inferences (both simple and complex) and understanding of intentionality, suggesting problems in higher-level comprehension $^{(13,16-18)}$. In particular, Attwood stated that "the person with Asperger's syndrome tends to make a literal interpretation of what the other person says, being greatly confused by idioms, irony, figures of speech, innuendo and sarcasm"(14) (p. 216). Similarly, studies show difficulties in tasks that require inferring about metaphors ${ }^{(10)}$ in explaining non-literal utterances, such as jokes, in a context-appropriate manner and in making contextually meaningful connections between linguistic information $^{(18)}$. However, it is important to note that the performance of individuals with AS/HFA indicates deficiencies in pragmatic comprehension and inference abilities, but not complete inability ${ }^{(18)}$. Consequently, AS/HFA individuals are able to answer some kinds of pragmatic questions, even if this ability is less developed than in typically developing children and adults. In fact, they prefer not to make inferences unless instructed to do so, or unless they need or decide to do so.

In the literature, the general consensus is that Theory of Mind (ToM) deficit can explain the severe difficulties in social interaction, communication and in pragmatic inferences ${ }^{(15,17)}$. The theory of mind refers to the ability to infer the full range of mental states (beliefs, desires, intentions, imagination, emotions, etc.) that cause action ${ }^{(19)}$. It is defined as the understanding of one's own and other people's beliefs, intentions and emotions ${ }^{(20)}$ and it has been commonly investigated by a variety of tasks and studies that focus on the corresponding conceptions within the child's developing understanding.

The problem with the comprehension of figurative language in children with AS/HFA, such as the problem with the interpretation of idioms, irony, metaphors, humor and sarcasm, lay on the literal interpretation of what the other person says $^{(14)}$. The literal interpretation results from deficits in ToM which have been observed in individuals with autism, across a range of age groups and IQ abilities ${ }^{(15,20)}$, and it is regarded as a core cognitive deficit in autism. The extent to which the autistic individuals could understand figurative language is dependent upon the level of theory of mind mastered ${ }^{(15)}$. In other words, the conversational abilities are related with TOM deficits. Children with autistic spectrum disorders are often unusually slow to acquire theory of mind abilities. Typical children are able to perform the first-order false-belief tasks well from age 5 onwards ${ }^{(21)}$ whereas, even in the absence of low IQ, those with autism are unlikely to do so until their teens, if not later. Also, even though individuals with AS/HFA seem 
able to understand a first-order false belief only some of them can successfully perform a second-order false belief task ${ }^{(17)}$. Second-order false-belief tasks require complex inferences to be made about someone's false attribution of belief.

The developmental changes that have been found in the understanding of mental state explain the developmental changes observed in idiomatic understanding. Apart from this, other factors that affect idioms' understanding are the verbal competences, the age and the type of idioms. Caillies and Le Sourn-Bissaoui ${ }^{(21)}$ found that the developmental changes in the comprehension of decomposable expressions by children were predicted by verbal competences and age but there was no indication that theory of mind competences determine their comprehension. However, theory of mind competences, and particularly second-order false belief success, were a significant predictor of the comprehension of non-decomposable expressions (after accounting for verbal competences). This means that children need vocabulary, adequate verbal IQ and recursive theory of mind to understand non-decomposable expressions. Concerning the type of idioms, there are three important dimensions that affect the ease of idiom acquisition and comprehension. The first dimension is compositionality, which refers to the ease with which literal word meanings of idiomatic expressions can be mapped onto components of idiomatic meaning once the idiomatic meaning has been apprehended and is clearly known. The second dimension is transparency which refers to the degree to which the original motivation of these phrases is immediately accessible. The third dimension concerns the literal plausibility. Familiarity ${ }^{(2,3,22,23)}$, that is, how frequently an individual is exposed to idioms and context $\mathrm{t}^{(6,24-26)}$ also plays significant roles in idiomatic comprehension and interpretation.

In the present study it was used a decontextualized multiple choice task, meaning a task where the idiom is presented in isolation, without a background story or sentence frame, where the participant have to select the appropriate meaning from a set of four drawings. The reason for using this type of task was that this task does not require verbal communication skills - which is a problematic area to children with pervasive developmental disorders - does not require reading comprehension skills and focuses only on the comprehension of idiom's figurative meaning. Also, it is well supported form previous studies that there are better results on multiple choice tasks than on definition tasks ${ }^{(23,27) .}$

The aim of the present study was to extend previous research on the development of idiom comprehension by investigating this ability in children with AS or HFA. The main research question that is posed is whether children with AS or HFA have difficulties in idiom comprehension comparing with a group of typically developing peers and with a group of adults. According to the literature which supports the im- pairments of children with AS or HFA in pragmatic skills and their tendency to make literal interpretations ${ }^{(10,13,14,28)}$, it can be assumed that the clinic group of the present study will have more difficulties in idiom comprehension when compared to the other two groups. The ensuing question concerns the degree of the difficulty and the qualitative error analysis. More specifically, the idiomatic phrases will be examined according to the number of wrong answers that each of them presents. Also, another question that is addressed concerns the developmental changes which are observed in relation to idiom comprehension. More specifically, the aim of the study was to investigate if there is a difference between typically developing children and adults concerning their performance to the task.

\section{METHODS}

\section{Participants}

Three groups participated in the study. All the participants were Greek, Christian Orthodox, their mother-tongue was Greek and they were males. The authors presented the current project to the candidate participants' parents. Afterwards, the parents gave their consent for their children to participate in the research bearing in mind the fact the participation was entirely voluntary and they could withdraw consent at any time without penalty. The first group consisted of 27 children who were diagnosed with AS/HFA with mean age 11.3 years $(\mathrm{SD}=2.55)$. The diagnoses were made by the child psychiatric team of Psychiatric Hospital of Thessaloniki (Greece). The researchers selected to include only those children that had intelligence within normal range according to Greek version of the Wechsler's intelligence scale (WISC-III). Children with AS/HFA took part in the same group because, according to the literature researched, they were expected to have similar pragmatic impairments ${ }^{(13)}$. Another reason was that the clinic group should have a satisfactory number of participants. All the participants were boys. In part, this choice was because of the difficulty in finding a sufficiently large number of girls with a diagnosis of high functioning autism. The participants in the other two groups had typical development. In particular, one consisted of 30 typically developing children (TDCH) with mean age 12.27 years ( $\mathrm{SD}=2.69)$, and the other consisted of 30 typically developed adults (TDA) with mean age 28.27 years $(\mathrm{SD}=7.84)$. The aim of using a group of adults was twofold. First, it was a matter of documenting the validity of the assessment tool and second, it would provide the opportunity to identify minor developmental changes (Table 1). More specifically, by using the adult group, the researchers aimed to confirm that the idiomatic expressions were known, the test was easy to be comprehended and simple in its structure.

Table 1. Age and WISC results of participants of the tree groups

\begin{tabular}{|c|c|c|c|c|c|}
\hline \multirow{2}{*}{ Groups } & \multicolumn{2}{|c|}{ Age } & \multicolumn{3}{|c|}{ Results from WISC-III } \\
\hline & Mean & SD & Minimum & Maximum & Mean \\
\hline Group with AS/HFA & 11.3 & 2.55 & 77.00 & 138.00 & 98.11 \\
\hline Group with TDCH & 12.27 & 2.69 & & in normal $r$ & \\
\hline Group with TDA & 28.27 & 7.84 & & in normal $r$ & \\
\hline
\end{tabular}

Note: $\mathrm{AS}=$ Asperger syndrome; HFA = high functioning autism; TDCH = typically developing children; TDA = typically developing adults; SD = standard deviation 


\section{Assessments}

The idiom comprehension was tested with the Comprehension Test of Idiomatic Phrases ${ }^{(29)}$. Due to the fact that this test has not been used in prior studies, it was administered in an adult group too, in order to control its validity. The test is composed of 22 Greek idiomatic phrases presented in isolation; the interviewee should show the correct answer in every item by choosing between four pictures which are presented to him for each phrase. Each phrase corresponds only to one of the four pictures. The other three pictures show the literal meaning of the phrase, a part of the meaning of the phrase and the opposite meaning of the phrase. The collection of the idiomatic phrases was made after researching books used in Greek primary schools. It is therefore likely that all the participants were familiar with these phrases, having heard them at least once.

\section{RESULTS}

In order to test for differences in task performance among the three independent groups, one-way analysis of variance (one-way ANOVA) was used. The results showed that children with AS/HFA had significantly lower performance compared both to the group of typically developing children (TDC) and to the group of typically developing adults (TDA). On the contrary, the post hoc tests found no difference in the performance between the two groups of typically developing participants (Table 2).

Table 2. Mean group performances

\begin{tabular}{llc}
\hline \multirow{2}{*}{ Groups } & \multicolumn{2}{c}{ Performance } \\
\cline { 2 - 3 } & Mean & SD \\
\hline Group with AS/HFA & 13.63 & 6.56 \\
Group with TDCH & 20.67 & 1.95 \\
Group with TDA & 21.90 & 0.30 \\
\hline
\end{tabular}

ANOVA: $F(2,84)=37.91, p<0.01$

Note: $\mathrm{AS}=$ Asperger syndrome; $\mathrm{HFA}=$ high functioning autism; $\mathrm{TDCH}=$ typically developing children; TDA = typically developing adults; $\mathrm{SD}$ = standard deviation

To test the performance in each item individually, the frequency of wrong answers was computed. For the group with AS/HFA the questions with the greater number of wrong answers were the $5^{\text {th }}$ and the $7^{\text {th }}$ with the $11^{\text {th }}$, the $20^{\text {th }}$ and the $22^{\text {nd }}$ to follow (Figure 1). When compared to the other groups the results showed that item 20 was difficult for all groups while item 22 followed with significant percentages of failure (Figure 1). To test if there was a relationship between the two groups of typically developing individuals and their performance in item 20 the Fisher's exact test was used. The results indicated that there was no significant relation between the two groups and their performance in the specific item (Exact Significance 2-sided, $\mathrm{p}=0.091$ ) (Figure 1).

Finally, the correlations between the variables age, IQ and performance were examined for the group of AS/HFA. The results revealed that age, but not IQ, had a positive correlation with the performance $(\mathrm{r}=0.50, \mathrm{p}<0.01)$. This correlation was

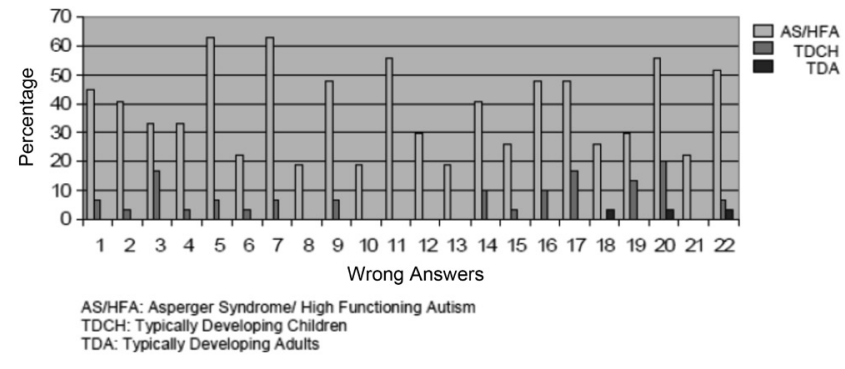

Figure 1. Frequencies of wrong answers.

tested with respect to the other two groups and the findings confirmed the positive correlation only for the control group of TDCH $(r=0.38, p<0.05)$.

\section{DISCUSSION}

The aim of the present study was to examine the comprehension of idioms in children with AS/HFA. As it has been already shown, the ability to process and acquire figurative language belongs to the domain of pragmatic skills. Undoubtedly, it is important to study difficulties in pragmatic inferencing, because they affect the individual's life widely, making it difficult to adequately communicate with peers and function in community.

Previous research has proven that idioms which are presented in supportive narrative contexts are easier to be comprehend than those presented in isolation, because context may provide the semantic information from which the listener can extract or infer the appropriate sense of the expression ${ }^{(5)}$. This study focused only in isolated idioms (idioms out of context), so the inference from context, a common strategy for the interpretation of idioms, was inapplicable. In this case, the participants should have relied mostly on semantic analysis (if the idiom was transparent). There are conflicting findings about the age at which semantic analysis can be used. Several studies show that this ability develops early at about 5 years of age ${ }^{(4)}$, while other studies indicate that development continues beyond 11 years of age ${ }^{(6,30)}$. Also, prior knowledge plays important role in idioms comprehension ${ }^{(6)}$. In the present study, the idiomatic expressions were collected from the books used in Greek primary schools, which ensures that all the participants were familiar with these expressions, having encountered them at least once. However, it is important to note that even if the meaning of an expression has been taught to someone directly, the ability to fully understand might require repeated exposure to the phrase in considerate and supportive contexts from which information can be extracted. It means that knowledge of an idiom's meaning may be built up gradually as children use the semantic analysis and/or exposure to context to derive meanings for unfamiliar and unknown expressions ${ }^{(5,7)}$. This is true especially for the children with AS/HFA who need not only repeated exposure, but clear explanations about the different meanings of a particular expression according to the context and the communicative act.

The present study proved that children with AS/HFA had serious difficulties in idiom comprehension, compared to typically developing peers and adults. This finding agrees with 
previous studies confirming that children with AS/HFA are less competent than their peers on idiom comprehension ${ }^{(28)}$ and on a range of pragmatic inference and language skills $^{(10,13,16)}$.

Also, this study showed that some specific expressions were more problematic to the group with AS/HFA. This finding may be due to the fact that some idioms are less common and the children have fewer opportunities to meet and to use them over and over again in order to fully understand them. Also, this finding may be explained by taking into account that the meaning of some idioms is not fully derivable through semantic analysis of the phrases. It is well known that opaque (semantically non-analyzable) idioms are hardly comprehended and their explanations are more accurate in the presence of $\operatorname{context}^{(6)}$.

On the other hand, children with AS/HFA were able to interpret correctly the meaning of some idioms, indicating that there may be difficulties in idiom comprehension but not a complete inability. This finding is in congruence with another study ${ }^{(28)}$ which concluded that the group with pragmatic impairments had a much greater percentage of "appropriate" than "inappropriate" responses in the play task items. This can be due to the fact that a great percentage of autistic expressive language is formulaic, which means that children can learn some expressions and use them as unanalyzed chunks. Also, this ability may be attributed to the idiom's familiarity which is linked to frequency of occurrence. Studies have proven that the more familiar an idiom is the easier it is to be interpreted correctly both by children and adults ${ }^{(7)}$. Also it should be taken into account the transparency of each idiom, as many studies have indicated that the semantically analyzable or transparent idioms were more easily comprehended ${ }^{(7,30)}$. Furthermore, it should be highlighted that idiom comprehension in children with AS/HFA is described as an inability in the literature by studies that aim to investigate and identify the problems and the disabilities of this specific clinical group. In fact, idiom comprehension is not an inability but a problematic area for the children with disorders of the autism spectrum.

Additionally, this study showed that the above difficulties can be evident in children with AS/HFA even if their intelligence is within normal range. Analysis of the data revealed that the correlation between the IQ and the task performance was not statistically significant. This finding is in agreement with the findings from other studies which indicate that even though individuals with AS/HFA demonstrate extensive spoken vocabularies and intact formal language skills ${ }^{(13)}$, they do have difficulties in the comprehension of figurative language.

The present findings are in disagreement with other studies $^{(2)}$ once it did not confirm discrepancies in the performance between the typically developing children and typical adults. It was found that the performance of the typically developing children was extremely high. Analysis of the error data revealed that the item with the greatest number of wrong answers for all groups was item 20 ("he gave the shoes on his hand"). This finding may result from the fact that the participants performed semantic analysis of this phrase, focusing on the concrete meaning of the particular words in the phrase (literal responses), which might also be correct and can be used with respect to the written and spoken contexts

However, concerning the developmental changes, the present findings showed, in accordance with another study ${ }^{(6)}$, that there was a positive correlation between age and performance for the two groups of children. This means that when idioms are presented without a supportive context, developmental differences are apparent.

The present study, despite its important findings, has some limitations. Firstly, the transparency, and the familiarity or the prior knowledge of idioms was not controlled. So the attribution of the performance to the more advanced skills has to be done with caution. Also, the sample of the study was small in order to be able to draw reliable conclusions that can be generalized. Furthermore, it should be taken into consideration the nature of the multiple-choice task, which simply required the examinee to recognize one correct picture out of four. So, some of the correct answers might be random. As stated before ${ }^{(27)} \mathrm{a}$ multiple choice task can be suggestive of a better performance in comparison to a definition task where the examinee has to paraphrase an idiom which may be presented in isolated form or within a context. The general consensus in studies which examine pragmatic skills is that the methods have to be sensitive enough in order to detect difficulties, since many of the individuals with AS/HFA can understand some idioms. This can sometimes mislead clinicians and others to think that there are no problems in pragmatic skills and in figurative language. Besides, it is well known that there is a great heterogeneity in linguistic skills in AS/HFA.

\section{CONCLUSION}

The results provide further evidence that children with AS/HFA have difficulties in understanding idioms and confirm their tendency to make literal interpretations. These impairments are irrelevant to their intelligence and affect their communication with others. The understanding of these difficulties is important in order to find ways to limit the confusion and the misinterpretations which are observed during the communicative acts with this clinical group. 


\section{RESUMO}

Objetivo: Ampliar pesquisas anteriores a respeito do desenvolvimento da compreensão de expressões idiomáticas por meio da investigação dessa habilidade em crianças com síndrome de Asperger (AS) ou com autismo de alto funcionamento (HFA). Métodos: Três grupos participaram do estudo. O primeiro grupo era composto por 27 crianças com AS/HFA (média de idade 11 anos e 3 meses) e os outros dois eram constituídos, respectivamente, por crianças em desenvolvimento típico e adultos. O Teste de Compreensão de Expressões Idiomáticas (CTIP) foi aplicado a todos os participantes. Resultados: Crianças com AS/HFA tiveram desempenho inferior ao dos participantes dos outros dois grupos. Nenhuma diferença foi observada no desempenho dos dois grupos típicos. Também não houve correlação significativa entre o QI e o desempenho de crianças com AS/HFA, enquanto foram observadas correlações positivas entre a performance e a idade para nos dois grupos de crianças. Conclusão: Os resultados oferecem mais evidências de que crianças com AS/HFA tem dificuldades para compreender expressões idiomáticas e confirmam sua tendência a fazer interpretações literais. Essas dificuldades são irrelevantes para sua inteligência, mas afetam sua comunicação com outros. A compreensão dessas dificuldades é importante para a identificação de mecanismos para diminuir as confusões e mal entendidos observados nos atos comunicativos desse grupo.

Descritores: Compreensão; Aptidão; Psicolinguística; Linguagem infatil; Cognição; Síndrome de Asperger; Transtorno autístico

\section{REFERENCES}

1. Glucksberg S. Understanding figurative language. Oxford: Oxford University Press; 2001.

2. Nippold MA, Duthie JK. Mental imagery and idiom comprehension: A comparison of school-age children and adults. J Speech Lang Hear Res. 2003;46(4):788-99.

3. Chan YL, Marinellie SA. Definitions of idioms in preadolescents, adolescents, and adults. J Psycholinguist Res. 2008;37(1):1-20.

4. Gibbs RW Jr. Semantic analyzability in children's understanding of idioms. J Speech Hear Res. 1991;34(3):613-20.

5. Levorato MC, Cacciari C. The effects of different tasks on the comprehension and production of idioms in children. J Exp Child Psychol. 1995;60(2):261-83.

6. Cain K, Towse AS, Knight RS. The development of idiom comprehension: An investigation of semantic and contextual processing skills. J Exp Child Psychol. 2009;102(3):280-98.

7. Nippold MA, Taylor CL. Judgments of idiom familiarity and transparency: a comparison of children and adolescents. J Speech Lang Hear Res. 2002;45(2):384-91.

8. Qualls CD, Lantz JM, Pietrzyk RM, Blood GW, Hammer CS. Comprehension of idioms in adolescents with language-based learning disabilities compared to their typically developing peers. J Commun Disord. 2004;37(4):295-311.

9. Gibbs RW. Interpreting what speakers say and implicate. Brain Lang. 1999;68(3):466-85.

10. Dennis M, Lazenby AL, Lockyer L. Inferential language in highfunction children with autism. J Autism Dev Disord. 2001;31(1):47-54.

11. Sperber D, Wilson D. Pragmatics, modularity and mind-reading. Mind Lang. 2002;17(1-2):3-23.

12. American Psychiatric Association. Diagnostic and Statistical Manual of Mental Disorders (DSM-IV). 4th ed. Washington (DC): American Psychiatric Association; 1994.

13. Loukusa S, Moilanen I. Pragmatic inference abilities in individuals with Asperger syndrome or high-functioning autism. A review. Res Autism Spectrum Disord. 2009;3(4):890-904.

14. Attwood T. Language. In: Attwood T. The complete guide to Asperger Syndrome. London: Jessica Kingsley Press; 2007. p. 202-27.

15. Happé FG. Communicative competence and theory of mind in autism: a test of relevance theory. Cognition. 1993;48(2):101-19.
16. Lewis FM, Woodyatt GC, Murdoch BE. Linguistic and pragmatic language skills in adults with autism spectrum disorder: A pilot study. Res Autism Spectrum Disord. 2008;2(1):176-87.

17. Le Sourn-Bissaoui S, Caillies S, Gierski F, Motte J. Inference processing in adolescents with Asperger syndrome: Relationship with theory of mind abilities. Res Autism Spectrum Disord. 2009;3(3):797-808.

18. Jolliffe T, Baron-Cohen S. A test of central coherence theory: Linguistic processing in high-functioning adults with autism or Asperger syndrome: Is local coherence impaired? Cognition. 1999;71(2):149-85.

19. Baron-Cohen S. Theory of mind and autism: a review. Int Rev Ment Retard. 2001;23:169-84.

20. Baron-Cohen S, Leslie AM, Frith U. Does the autistic child have a "theory of mind"? Cognition. 1985;21(1):37-46.

21. Caillies S, Le Sourn-Bissaoui S. Children's understanding of idioms and theory of mind development. Dev Sci. 2008;11(5):703-11.

22. Gibbs RW. What do idioms really mean? J Mem Lang. 1992;31(4):485506.

23. Nippold MA, Rudzinski M. Familiarity and transparency in idiom explanation: A developmental study of children and adolescents. J Speech Hear Res. 1993;36(4):728-37.

24. Ackerman BP. On comprehending idioms: do children get the picture? J Exp Child Psychol. 1982;33(3):439-54.

25. Laval V. Idiom comprehension and metapragmatic knowledge in French children. J Pragmatic. 2003;35(5):723-39.

26. Qualls CD, Treaster B, Blood GW, Hammer CS. Lexicalization of idioms in urban fifth graders: a reaction time study. J Commun Disord. 2003;36(4):245-61.

27. Kerbel D, Grunwell P. A study of idiom comprehension in children with semantic-pragmatic difficulties. Part I: Between-groups results and discussion. Int J Lang Commun Disord. 1998;35(1):1-22.

28. Kerbel D, Grunwell P. A study of idiom comprehension in children with semantic-pragmatic difficulties. Part II: Task effects on the assessment of idioms comprehension in children. Int J Lang Commun Disord. 1998;35(1):23-44.

29. Vogindroukas I, Kariotidis C. Comprehension test of idiomatic phrases. Ioannina: Technological Institute of Epirus; 2006.

30. Levorato MC, Cacciari C. Idiom comprehension in children: Are the effects of semantic analysability and context separable? Eur J Cogn Psychol. 1999;11(1):51-66. 